\title{
Perbandingan Nilai Urin Puasa dan Urin Acak Pada Penderita DM (DIABETES MELLITUS) Menggunakan Metode Resistansi dan Perbedaan Warna RGB Berbasis Arduino
}

\author{
Humaidillah Kurniadi Wardana \\ Jurusan Teknik Elektro, Fakultas Teknik, Universitas Hasyim Asy’ari, \\ E-mail: adi3_wardana@yahoo.com
}

\section{Elly Indahwati}

Jurusan Teknik Elektro, Fakultas Teknik, Universitas Hasyim Asy’ari,

E-mail: elly.indahwati@mail.ugm.ac.id

\section{Lina Arifah Fitriyah}

Jurusan Pendidikan IPA, Fakultas Ilmu Pendidikan, Universitas Hasyim Asy'ari, E-mail: muna_arifah@yahoo.co.id

\begin{abstract}
Abstrak
Pengukuran kadar glukosa dalam urin pada penelitian ini menggunakan prinsip resistansi dan perbedaan warna berdasarkan RGB nya. Pengukuran dilakukan dengan menggunakan urin puasa dan urin acak. Nilai resistansi diperoleh dari sel elektroda yang dihubungkan pada salah satu lengan rangkaian jembatan wheatstone dan warna didapatkan dari sensor tcs3200 yang dihubungkan pada arduino uno dan ditampilkan pada lcd 16x4. Hasil pengukuran menunjukkan bahwa nilai urin acak lebih tinggi dua kali lipat dari urin puasa dan hasil deteksi warna untuk penderita DM urin berwarna biru sedangkan yang tidak DM berwarna merah.
\end{abstract}

Kata Kunci: Urin, DM, Resistansi, RGB, Arduino.

\section{PENDAHULUAN}

Kadar gula darah erat hubungannya dengan penyakit diabetes mellitus (DM) atau yang dikenal secara luas dengan nama kencing manis. Penyakit DM timbul pada seseorang disebabkan karena naiknya kadar glukosa darah sebagai akibat penurunan sekresi insulin yang progresif (American Diabetes Association, 2015). Gula darah berada di dalam tubuh berasal dari karbohidrat yang ada dalam makanan dan disimpan dalam bentuk glikogen di dalam hati dan otot rangka (Kee, 2007). Batas kadar gula dalam darah yang dibolehkan dalam tubuh berkisar 90$120 \mathrm{mg} / \mathrm{dl}$ (Aditta dkk, 2013). Kadar gula darah tinggi disebut hiperglikemia sedangkan kadar gula terlalu rendah disebut hipoglikemia (Sukandar dkk, 2009).

\section{Abstract}

Measurements of the levels of glucose in the urine in this study uses the principle of resistance and the difference in color based on RGB. The measurement is carried out using urine fasting and random urine. The resistance measurements show that the value of the higher random urine twice as fast, and the results of the urine color detection for sufferers of DM blue urine while not DM is red.

Keywords: Urine, DM, Resistance, RGB, Arduino.

Secara medis pengecekan kadar gula darah dapat dilakukan dua cara yaitu dengan cara invasive dan noninvasive. Metode invasive adalah teknik melukai dengan cara melukai tubuh pasien dengan menggunakan jarum dan mengambil darahnya untuk diukur kadar glukosa yang terkandung dalam darah. Kelemahan metode ini mengakibatkan rasa sakit pada tubuh pasien dan efek psikologis pada pasien yang memiliki rasa takut pada jarum suntik. Sedangkan metode non-invasive menggunakan teknik biofluids dengan cara mengambil cairan dalam tubuh berupa air ludah, air mata, keringat dan urin sehingga pasien merasa nyaman dengan menggunakan teknik ini (John C.P dkk, 2005), (Park H.D dkk, 2005).

Urin merupakan hasil cairan sisa hasil ekskresi ginjal yang dikeluarkan dari tubuh memalui proses urineasi. 
Eksresi urin diperlukan untuk membuang molekulmolekul sisa dalam darah yang disaring oleh ginjal dan untuk menjaga homeostatis cairan tubuh. Urin disaring di dalam ginjal, di bawah memalui ureter menuju kandung kemih, akhirnya dibuang keluar tubuh melalui uretra (S. Notoatmojo, 2000). Dari urin inilah dapat menghasilkan sebuah informasi mengenai kadar glukosa yang menimbun dalam darah, akan keluar melalui urin dan terdeteksi pada tes urin melalui kepekatan, warna, dan kejernihan. Secara normal urin berwarna kuning muda dan kejernihan jernih atau sedikit keruh.

Pendeteksian kadar glukosa dalam urin telah dikembangkan dan diteliti dengan menggunakan metode spektroskopi menggunakan sinar inframerah (NIR) dan photodioda diantaranya adalah Riza Tahmridho (2010), Anas dkk (2012), R.A Buda dan M.Mohd. Addi (2014), Komal Lawand dkk (2015). Sedangkan penelitian yang menggunakan teknik pergeseran dari metode optik menggunakan sensor fiber untuk mengukur kadar glukosa diantaranya adalah Fina Nurul Aini dkk (2012), Ninik Irawati dkk (2012).

Resitansi diukur dan didapatkan dari rangkaian jembatan wheatstone berbentuk belah ketupat. Rangkaian belah ketupat ini berupa 4 resistor (hambatan) yang posisinya bersilangan. Prinsip dasar dari jembatan wheatstone adalah keseimbangan. Salah satu lengan jembatan wheastone yang berisi resistor diganti dengan 2 buah elektroda tembaga yang nantinya 2 elektroda ini dimasukkan ke dalam urin yang ditampung dalam sebuah wadah. Perubahan pada salah satu lengan jembatan wheatstone mengakibatkan perubahan tegangan keluaran (Vout) yang kemudian dikuatkan oleh penguat instrumentasi. Warna dari urin nantinya dideteksi oleh sensor TCS3200. Sensor TCS3200 merupakan IC yang dapat diprogram yang cara kerjanya mengkonversi warna cahaya ke frekuensi dengan output berbentuk sinyal kotak. Penyusun utama sensor warna ini adalah photodiode dan pengkonversi arus ke frekuensi. Sensor warna TCS3200 merupakan sensor warna cahaya yang dilengkapi dengan filter cahaya untuk warna dasar RGB (Dede Sutisna dkk, 2015).

Pada penelitian ini akan disajikan perbandingan pengukuran urin puasa dan acak pada penderita DM menggunakan metode resistansi dan perbedaan warna RGB. Pengukuran dengan metode ini diharapkan dapat menghasilkan informasi yang digunakan untuk proses pengukuran kadar glukosa pada penderita DM tanpa rasa sakit dan aman digunakan.

\section{METODE}

Perangkat penelitian ini terdiri dari sampel urin puasa dan acak, sel elektroda, rangkaian jembatan wheatstone, penguat tegangan, sensor tcs3200, arduino uno, dan lcd 16x4. Prinsip kerja dari alat ukur kadar glukosa dalam urin ini secara umum dapat dijelaskan pada Gambar 1.

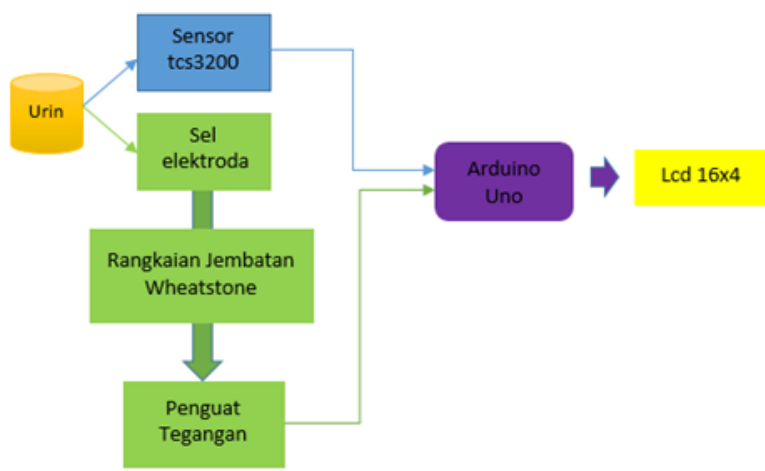

Gambar 1. Blok Diagram Alat Pengukur Kadar Glukosa

Pengukuran dimulai saat wadah urin diisi oleh sampel urin dengan volume $\pm 50 \mathrm{ml}$ dan ditutup rapat sehingga sel elektroda yang menempel pada tutup wadah urin mengenai urin begitu juga dengan sensor tcs3200 yang menempel pada wadah urin. Besarnya resistansi diperoleh dari sel elektroda yang mengenai urin yang dirangkai pada salah satu lengan rangkaian jembatan wheatsone dan dikuatkan oleh penguat tegangan. Sedangkan warna urin dideteksi oleh sensor tcs3200. Nilai resistansi berupa tegangan dalam $\mathrm{mV}$ dan warna RGB diproses dan dihitung oleh arduino uno sehingga didapatkan hasil pengukuran yang ditampilkan pada lcd. Nilai tegangan $(\mathrm{mV})$ nantinya dikonversi ke nilai kadar gula darah dalam satuan $\mathrm{mg} / \mathrm{dl}$ dengan menggunakan persamaan 1 sebagai berikut:

$$
\frac{X-X_{1}}{X_{2}-X_{1}}=\frac{Y-Y_{1}}{Y_{2}-Y_{1}}
$$

Keterangan:

$\mathrm{X}_{1} \quad=$ Tegangan untuk urin normal (-)

$\mathrm{X}_{2}=$ Tegangan untuk urin penderita diabetes tertinggi $(++++)$

$\mathrm{Y}_{1}=$ Nilai urin normal berdasarkan hasil lab dalam satuan $\mathrm{mg} / \mathrm{dl}$

$\mathrm{Y}_{2}=$ Nilai urin penderita diabetes tertinggi $(++++)$ berdasarkan hasil lab dalam satuan $\mathrm{mg} / \mathrm{dl}$.

Pengukuran dilakukan terhadap urin puasa dan urin acak yang kemudian hasilnya dibandingkan dengan hasil lab dari RSUD. Dr. H. Moh Anwar Kabupaten Sumenep dengan menggunakan metode carik celup analiser. Realisasi alat ukur kadar glukosa dalam urin ditunjukkan Gambar 2. 


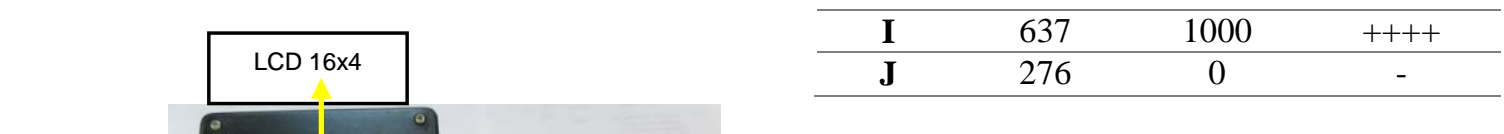

Tabel 4. Hasil Pengukuran Resistansi Urin Acak

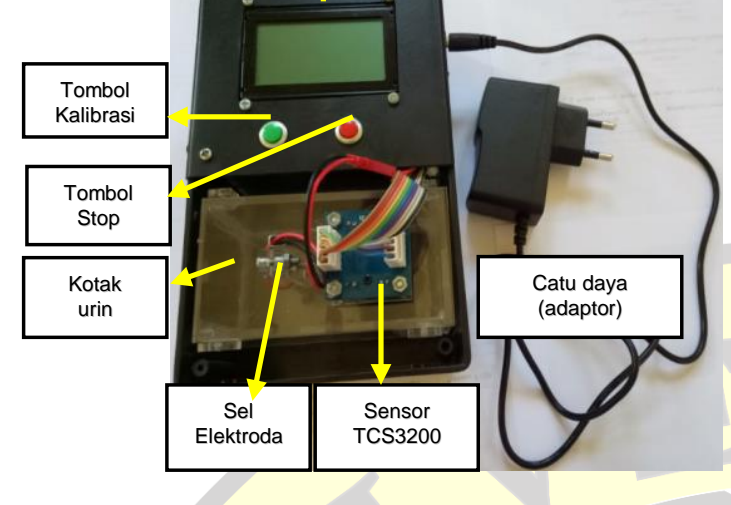

Gambar 2. Realisasi Alat Ukur Kadar Glukosa Urin

\section{HASIL DAN PEMBAHASAN}

Data hasil pengukuran kadar glukosa dalam urin berupa resistansi dalam tegangan $(\mathrm{mV})$ dan warna $\mathrm{RBG}$ dapat dilihat sebagai berikut:

a. Hasil pengukuran urin puasa

Tabel 1. Hasil Pengukuran Resistansi Urin Puasa

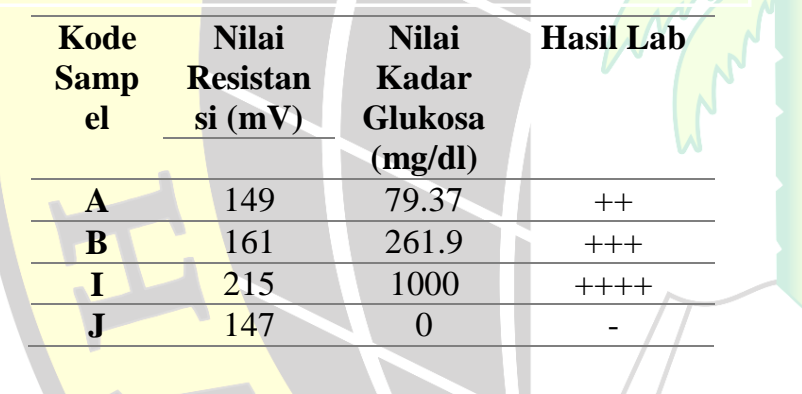

Tabel 2. Hasil Pengukuran Warna Urin Puasa

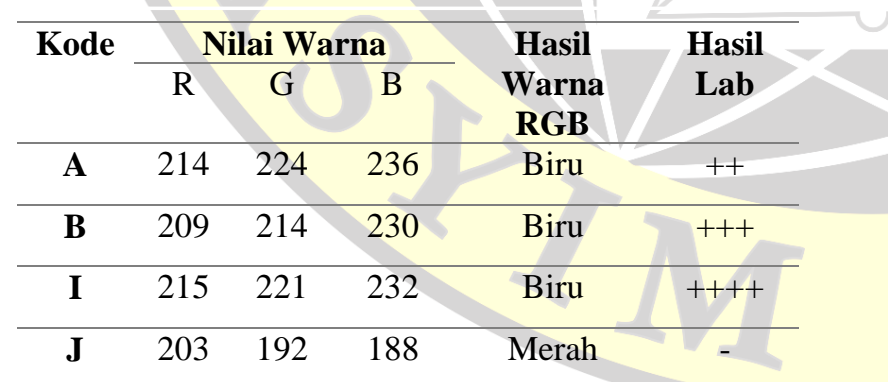

b. Hasil pengukuran urin acak

Tabel 3. Hasil Pengukuran Resistansi Urin Acak

\begin{tabular}{cccc}
\hline $\begin{array}{c}\text { Kode } \\
\text { Sampe } \\
\mathbf{l}\end{array}$ & $\begin{array}{c}\text { Nilai } \\
\text { Resistan } \\
\text { si (mV) }\end{array}$ & $\begin{array}{c}\text { Nilai } \\
\text { Kadar } \\
\text { Glukosa } \\
\text { (mg/d) })\end{array}$ & Hasil Lab \\
\hline A & 350 & 275.34 & +++ \\
\hline B & 356 & 293.49 & +++ \\
\hline
\end{tabular}

\begin{tabular}{|c|c|c|c|c|c|}
\hline \multirow[t]{2}{*}{ Kode } & \multicolumn{3}{|c|}{ Nilai Warna } & \multirow{2}{*}{$\begin{array}{c}\text { Hasil } \\
\text { Warna } \\
\text { RGB }\end{array}$} & \multirow{2}{*}{$\begin{array}{c}\text { Hasil } \\
\text { Lab }\end{array}$} \\
\hline & $\mathrm{R}$ & $\mathrm{G}$ & B & & \\
\hline $\mathbf{A}$ & 214 & 224 & 236 & Biru & +++ \\
\hline B & 209 & 214 & 230 & Biru & +++ \\
\hline I & 205 & 207 & 219 & Biru & ++++ \\
\hline $\mathbf{J}$ & 212 & 192 & 188 & Merah & - \\
\hline
\end{tabular}

Berdasarkan hasil dari Tabel 1 dan Tabel 2 didapatkan pengukuran resistansi untuk urin puasa untuk sampel A sebesar $149 \mathrm{mV}$, kadar glukosa dalam urin sebesar $79.37 \mathrm{mg} / \mathrm{dl}$ dan hasil lab menunjukkan hasil positif dua $(++)$, dengan warna biru. Sampel B sebesar $161 \mathrm{mV}$, kadar glukosa dalam urin sebesar $261.9 \mathrm{mg} / \mathrm{dl}$ dan hasil lab menunjukkan hasil positif tiga (+++), dengan warna biru. Sampel I sebesar $215 \mathrm{mV}$, kadar glukosa dalam urin sebesar $1000 \mathrm{mg} / \mathrm{dl}$ dan hasil lab menunjukkan hasil positif empat $(++++)$, dengan warna biru. Sedangkan Sampel J sebesar $147 \mathrm{mV}$, kadar glukosa dalam urin sebesar $0 \mathrm{mg} / \mathrm{dl}$ dan hasil lab menunjukkan hasil negatif (), dengan warna merah.

Pada Tabel 3 dan Tabel 4 didapatkan pengukuran resistansi untuk urin acak untuk sampel A sebesar 350 $\mathrm{mV}$, kadar glukosa dalam urin sebesar $275.34 \mathrm{mg} / \mathrm{dl}$ dan hasil lab menunjukkan hasil positif tiga $(+++)$, dengan warna biru. Sampel B sebesar $356 \mathrm{mV}$, kadar glukosa dalam urin sebesar $293.49 \mathrm{mg} / \mathrm{dl}$ dan hasil lab menunjukkan hasil positif tiga $(+++)$, dengan warna biru. Sampel I sebesar $637 \mathrm{mV}$, kadar glukosa dalam urin sebesar $1000 \mathrm{mg} / \mathrm{dl}$ dan hasil lab menunjukkan hasil positif empat (++++), dengan warna biru. Untuk Sampel J sebesar $276 \mathrm{mV}$, kadar glukosa dalam urin sebesar 0 $\mathrm{mg} / \mathrm{dl}$ dan hasil lab menunjukkan hasil negatif (-), dengan warna merah.

Dari penjelasan diatas maka ada kenaikan nilai resistansi yang signifikan antara sampel urin puasa dan urin acak yang digunakan. Hasil pengukuran menunjukkan sekitar 2 kali kenaikan nilai resistansi. Untuk yang didiagnosa DM berdasarkan hasil pengukuran dari alat yang dibuat dibandingkan dengan hasil lab ditunjukkan oleh tanda positif sedangkan yang tidak didiagnosa DM ditunjukkan tanda negatif. Artinya secara medis menunjukkan tanda $(-)=0 \mathrm{mg} / \mathrm{dl},(+)=1 \mathrm{mg} / \mathrm{dl}$ sampai $50 \mathrm{mg} / \mathrm{dl},(++)=51 \mathrm{mg} / \mathrm{dl}$ sampai $100 \mathrm{mg} / \mathrm{dl}$, $(+++)=101 \mathrm{mg} / \mathrm{dl}$ sampai $300 \mathrm{mg} / \mathrm{dl},(++++)=301$ $\mathrm{mg} / \mathrm{dl}$ sampai $1000 \mathrm{mg} / \mathrm{dl}$. Sedangkan untuk warna berdasarkan deteksi dari sensor tcs3200 menunjukkan 
secara keseluruhan dari urin puasa dan acak yang didiagnosa DM berwarna biru dan yang tidak didiagnosa DM berwarna merah.

\section{Ucapan Terima Kasih}

Ucapan terima kasih yang sebesar-besarnya atas pendanaan penelitian ini yang diberikan dari DRPM, Kemenristekdikti melalui Penelitian Dosen Pemula (PDP) tahun 2017 dan RSUD dr. H. Moh Anwar Kabupaten Sumenep sebagai patner dalam pengambilan sampel dan data.

\section{PENUTUP}

\section{Simpulan}

Nilai resistansi dari urin puasa berada disekitar 140 s/d $200 \mathrm{mV}$ dengan nilai kadar glukosa dalam urin - (0 $\mathrm{mg} / \mathrm{dl}), \quad++(79,37 \mathrm{mg} / \mathrm{dl}),+++(261,9 \mathrm{mg} / \mathrm{dl}),++++$ $(1000 \mathrm{mg} / \mathrm{dl})$. Sedangkan untuk nilai resistansi urin acak berada disekitar $240 \mathrm{~s} / \mathrm{d} 590 \mathrm{mV}$ dengan nilai kadar glukosa dalam urin - $(0 \mathrm{mg} / \mathrm{dl}),+++(275 \mathrm{mg} / \mathrm{dl}),++++$ $(1000 \mathrm{mg} / \mathrm{dl})$. Warna urin pada penderita DM dideteksi warna biru sedangkan yang tidak berwarna DM dideteksi warna merah.

\section{Saran}

Penelitian lanjutan perlu dilakukan variasi bahan dan luasan elektroda yang bermacam-macam sehingga mendapatkan nilai yang pasti serta sampel pasien DM perlu ditingkatkan jumlahnya agar mendapatkan hasil yang kompetibel.

\section{DAFTAR PUSTAKA}

Aini, Fina Nurul., Samian., and Yasin, Moh. 2012. Pengukuran Kadar Glukosa dalam Air Destilasi Menggunakan Fiber Coupler. Prosiding Semnas Fisika Terapan III Departemen Fisika FST Unair. ISBN: 978-979-17494-2-8.

Anas dkk, M.N. 2012. Non-Invasive Blood Glucose Measurement. IEEE Conference on Sustainble Utilization and Development in Engineering and Technology (Student) Universiti Tunku Abdul Rahman, Kuala Lumpur Malaysia. 978-1-4673$1705-4 / 12 / \$ 31.00$.

Amerikacan Diabetes Association. 2015. Classification and Diagnosis of Diabetes. Diabetes Care. Vol 38 (Suppl.1).S8-16.

Aulia Haque, Aditta Putri dkk. 2013. Analisis Profil Potensial Listrik Pada Titik Akupuntur Untuk Diagnosis Diabetes Mellitus. Jurnal Fisika dan Terapannya Fisika Unair. Vol. 1. No. 4. Hal. 1. Desember 2013.
Buda, R.A. and Mohd.Addi, M. 2014. A Portable NonInvasive Blood Glucose Monitoring Device. IEEE Conference on Biomedical Engineering an Sciences Sarawak Malaysia. 978-1-4799-40844/14.

C.P. John dkk. 2005. In vivo Glucose Monitoring: The Clinical Reality and The Promise, Biosens. Bioelectron. 20 (2005) 1897-1902.

H.D. Park dkk, K.J. 2005. Design of portable Urine Glucose Monitoring System for Healthcare, Comput. Biol. Med. 35 (2005) 275-286.

Irawati, Ninik., Saraswati, Delima Ayu., and Ysin, Moh. Rancang Bangun Alat Pengukur Kadar Gula Darah Menggunakan Metode Optik Untuk Penderita Diabetes. Prosiding Semnas Fisika Terapan III Departemen Fisika FST Unair. ISBN: 978-979-17494-2-8.

Kee, Joyce LeFever. 2007. Pedoman Pemeriksaan Laboratorium \& Diagnostik. Edisi 6. Jakarta: EGC.

Lawand, Komal dkk. 2015. Design And Development of Infrared LED Based Non Invasive Blood Glucometer. IEEE Indicon. 1570186243.

Notoatmojo, S. 2000. Metodelogi Penelitian Kesehatan. Jakarta: Rineka Cipta.

Sukandar, E.Y, dkk. 2009. ISO Farmakoterapi. Jakarta: PT. ISFI.

Sutisna, Dede., and Ihasanto, Eko. 2015. Perancangan dan Pembuatan Alat Pendeteksi Warna Menggunakan Sensor TCS3200 Pada Proses Produksi Kaleng Berbasis Arduino. Tugas Akhir: Program Studi Teknik Elektro Universitas Mercu Buana Jakarta

Tamridho, Reza. 2010. Rancang Bangun Alat Pengukur Kadar Gula Darah. Skripsi Fakultas Teknik Program Studi Teknik Elektro UI Depok. 